\title{
Dual factor pulse pressure: body mass index and outcome in type 2 diabetic subjects on maintenance hemodialysis. A longitudinal study 2003-2006
}

\author{
Lydia Foucan ${ }^{1,2}$ \\ Kheira Hue \\ Jocelyn Inamo' \\ Jacqueline Deloumeaux ${ }^{1,2}$ \\ Anne Blanchet-Deverly ${ }^{1,4}$ \\ Henry Merault ${ }^{3}$ \\ Jean-Marc Gabriel ${ }^{5}$ \\ 'Research group Clinical Epidemiology \\ and Medicine of the University of \\ Antilles and Guyane, French West \\ Indies; ${ }^{2}$ Department of Medical \\ Information and Public Health; \\ ${ }^{3}$ Nephrology and hemodialysis Unit; \\ ${ }^{4}$ Cardiology Unit, $\mathrm{CHU}$ of Pointe-à- \\ Pitre, Guadeloupe, French West Indies; \\ ${ }^{5}$ Hemodialysis Unit, Clinic of Choisy \\ Sainte Anne, Guadeloupe, French West \\ Indies
}

Correspondence: Dr Lydia Foucan Département d'Information Médicale, Pole Santé Publique, Recherche, $\mathrm{CHU}$ de Pointe-à-Pitre, 97। 59 Pointe-à-Pitre Guadeloupe, French West Indies Tel +590 89 I $534 /$ +590 89 I5 76 Fax $+59089 \quad 1595$

Email Ifoucan@yahoo.fr
Background: Inverse associations between risk factors and mortality have been reported in epidemiological studies of patients on maintenance hemodialysis (MHD).

Objective: The aim of this prospective study was to estimate the effect of the dual variable pulse pressure (PP) - body mass index (BMI) on cardiovascular (CV) events and death in type 2 diabetic (T2D) subjects on MHD in a Caribbean population.

Methods: Eighty Afro-Caribbean T2D patients on MHD were studied prospectively from 2003 to 2006. Proportional-hazard modeling was used.

Results: Of all, 23.8\% had a high PP (PP $\geq 75$ th percentile), $76.3 \%$ had BMI $<30 \mathrm{Kg} / \mathrm{m}^{2}$, $21.3 \%$ had the dual factor high PP - absence of obesity. During the study period, 23 patients died and $13 \mathrm{CV}$ events occurred. In the presence of the dual variable and after adjustment for age, gender, duration of MHD, and pre-existing CV complications, the adjusted hazard ratio (HR) $(95 \% \mathrm{CI})$ of $\mathrm{CV}$ events and death were respectively $2.7(0.8-8.3) ; P=0.09$ and 2.4 $(1.1-5.9) ; P=0.04$.

Conclusions: The dual factor, high PP - absence of obesity, is a prognosis factor of outcome. In type 2 diabetics on MHD, a specific management strategy should be proposed in nonobese subjects with wide pulse pressure in order to decrease or prevent the incidence of fatal and nonfatal events.

Keywords: dual factor, pulse pressure, body mass index, type 2 diabetes, outcome

\section{Introduction}

Type 2 diabetes (T2D) is a rapidly growing health problem in Guadeloupe and is highly prevalent in patients on maintenance hemodialysis (MHD) as found in countries with a western lifestyle (Foucan et al 2000).

Traditional risk factors of cardiovascular disease (CVD) in the general population, such as hypertension, obesity, and hypercholesterolemia, were previously associated with better survival on dialysis (Kalantar-Zadeh et al 2005; Nurmohamed 2005). This inverse association between clinical risk factors and mortality has been reported in several epidemiological studies of dialysis patients (Kalantar-Zadeh et al 2003, 2005; Kopple 2005). Thus, in subjects on MHD, weight gain and baseline obesity have been associated with a reduced cardiovascular risk with a lowest mortality in morbidly obese patients (Kalantar-Zadeh et al 2005). Hypertension is a common co-morbid condition in dialysis patients. In diabetic patients with chronic kidney disease, the blood pressure treatment goal is less than 130/80 mmHg (Chobanian et al 2003; Prisant 2003). But, in patients on MHD, the hypertension contribution to a poor prognosis is controversial. A time effect is evocated with a high risk of early mortality for hypotension and a 
high risk of late mortality for hypertension (Zager et al 1998; Charra 2007). Some authors reported that pulse pressure (PP), an indicator of arterial stiffness (Nawrot et al 2004), was an independent predictor of total mortality in nondiabetic patients on MHD (Tozawa et al 2002). Some others, in a clinical review, highlighted the potential dangers of extrapolating trials findings from nonkidney disease patients to those with chronic kidney disease (Kaisar et al 2007).

Studies of patients on MHD are more often conducted on overall populations with diabetes status considered as a covariate. Further more to our knowledge, the prognosis significance of the dual factor body mass index (BMI) - PP has not yet been reported in T2D subjects undergoing HD.

The present study was conducted in Guadeloupe, a French Caribbean island of 420,000 inhabitants. On this island, about $30 \%$ of the 400 individuals receiving renal replacement therapy are diabetics and the majority of them have T2D.

We hypothesized that the combination of a BMI less than $30 \mathrm{~kg} / \mathrm{m}^{2}$ and a wide pulse pressure at baseline are independently associated with cardiovascular (CV) events and total mortality in T2D patients undergoing hemodialysis with a higher risk for this dual factor than for each of them considered separately.

\section{Patients and method}

A longitudinal study was conducted in Guadeloupe during the period of December 2003 through December 2006.

\section{Study population}

The study population was constituted of subjects alive on December 2003, and who had been treated for more than one month in dialysis. They were 33 to 80 -years-old and were selected in 3 dialysis centers of the island. Dialysis was performed three times per week. The diabetic status was a co-morbid condition or an etiology of chronic kidney disease. The sample represented nearly $85 \%$ of the T2D patients on HD in the island and was previously described in a cross sectional study at baseline (Foucan et al 2005).

\section{Data collection}

Demographic, clinical and laboratory data were collected on all T2D patients on dialysis on December 2003 and dialyzed for more than 1 month. Data collected were: age, gender, years on chronic HD prior to December 2003, history of disease (hypertension, stroke, and coronary disease), use of current antidiabetic and antihypertensive treatment.

Height, weight were measured. The BMI, weight/height ${ }^{2}$ $\left(\mathrm{kg} / \mathrm{m}^{2}\right)$ was calculated.

\section{Blood pressure}

We have taken into account systolic (SBP) and diastolic blood pressure (DBP) recorded at baseline with an automated method before HD for every single observed HD. The retained values were the average systolic and average diastolic pressures over a month period.

\section{Definition of clinical factors and outcome data}

Pulse pressure was calculated as SBP - DBP (mmHg). High pulse pressure corresponded to a PP equal or higher than the 75th percentile of the overall PP values for each gender.

Hypertension was defined as a SBP $\geq 140$ or a DBP $\geq$ $90 \mathrm{mmHg}$ or history of hypertension and current use of antihypertensive medication.

Obesity was defined as BMI $\geq 30 \mathrm{~kg} / \mathrm{m}^{2}$ and morbid obesity as BMI $\geq 40 \mathrm{~kg} / \mathrm{m}^{2}$.

The dual factor was defined as the following combination: $\mathrm{PP} \geq 75$ th percentile $-\mathrm{BMI}<30 \mathrm{~kg} / \mathrm{m}^{2}$.

Outcome data were obtained from medical record. Cardiovascular events included coronary artery disease (angina pectoris, acute myocardial infarction, coronary bypass surgery, or coronary angioplasty), stroke and death related to $\mathrm{CV}$ events. Cardiovascular death was defined as death from coronary disease or stroke.

Pre-existing CV complications included cardiac events (coronary event and stroke) occurred before December 2003.

All patients were followed up until coronary events, stroke, death for all causes, or transfer out of Guadeloupe or the end of 2006.

\section{Statistical analysis}

The descriptive statistics of patient characteristics were performed. The results were expressed as median (IQR: interquartile range) for the continuous variables and by number (percentage) for the categorical variables. The subjects were divided into two groups according to the occurrence or not of events. The chi-square test and the Mann Whitney nonparametric test were used to compare ratios and values between patients groups. Correlation between continuous variables was tested with Pearson correlation coefficient.

Cox proportional hazard modeling was used, to assess the risk of $\mathrm{CV}$ events or death in patients with the highest values of PP, in those without obesity and in those with the dual factor high $\mathrm{PP}-\mathrm{BMI}<30 \mathrm{~kg} / \mathrm{m}^{2}$. Unadjusted and adjusted hazard ratios and $95 \%$ confidence interval, $\mathrm{HR}(95 \% \mathrm{CI})$ were calculated. Adjusted analyses were performed with other covariates: gender, age (/10-year increase), time on dialysis 
( $\geq 3$ years or $<3$ years) pre-existing $\mathrm{CV}$ complications at baseline. Graphical and statistical tests were used to check the assumption of proportional hazards.

SPSS V 15.0 statistical software package (SPSS Inc., Chicago, IL, USA) was used for data analysis.

A $P$ value $<0.05$ was considered as significant.

\section{Results}

Overall 80 T2D subjects were included in the study. The population was $58 \%$ female. The mean (SD) age at baseline was 62 (31) years: Tables 1 shows the baseline characteristics of the sample of T2D. Of the subjects, 75 (94\%) had hypertension and among them, $84 \%$ were treated. Most of the subjects received angiotensin-converting enzyme inhibitors or calcium channel blockers. Among those receiving antihypertensive medications, 5 (7.9\%) had a blood pressure less than 130/80 $\mathrm{mmHg}$. No significant difference in frequencies of hypertension and use of antihypertensive drugs was found between subjects with occurrence of CV events and those who died.

Median pulse pressure (IQR) was 75 (63-87) $\mathrm{mmHg}$ in the overall study sample. There was no significant difference in frequencies of high PP in the 3 BMI classes (25\% for $\mathrm{BMI}<25,30 \%$ for $25 \leq \mathrm{BMI}<30$ and $11 \%$ for BMI $\geq 30 \mathrm{~kg} / \mathrm{m}^{2}$ ). Of all, $23.8 \%$ of the subjects had a high PP, 76\% were nonobese, $21 \%$ had the dual factor high PP - absence of obesity. Four subjects (5\%) had a morbid obesity and didn't present outcome during the study period.

Pre-existing CV complications were noted in 30 subjects (16 coronary events, 18 strokes).

During the three year follow-up period, 23 patients died and $13 \mathrm{CV}$ events occurred: 1 nonfatal acute myocardial infarction (AMI), 6 fatal AMI, 2 angina (who undergone coronary angioplasty), and 3 nonfatal and 1 fatal ischemic strokes.

There was no significant correlation between BMI and PP.

\section{Comparison between groups}

Comparison between patient groups without (group1) and with (group 2) events (Table 1) didn't show significant differences for median BMI and median blood pressure components.

Table I Characteristics of the type 2 diabetic subjects on chronic maintenance hemodialysis $(\mathrm{N}=80)$

\begin{tabular}{|c|c|c|c|c|}
\hline & \multirow{3}{*}{$\begin{array}{l}\text { All } \\
\mathbf{N}=\mathbf{8 0}\end{array}$} & \multicolumn{3}{|c|}{ Incidence of cardiovascular events or death } \\
\hline & & No & Yes & $P$ \\
\hline & & $\mathbf{N}=\mathbf{5 4}$ & $N=26$ & \\
\hline \multicolumn{5}{|l|}{ Quantitative parameters* } \\
\hline Age years & $62(55-70)$ & $6 I(53-7 \mid)$ & $65(60-70)$ & 0.28 \\
\hline BMI kg/m² & $26(23-30)$ & $27(23-31)$ & $26(22-29)$ & 0.20 \\
\hline Duration of dialysis (years) & $2(I-4)$ & $2(1-4.2)$ & $2(0.5-4)$ & 0.97 \\
\hline SBP $m m ~ H g$ & $15 \mid(14 \mid-167)$ & $153(142-165)$ & $156(142-169)$ & 0.36 \\
\hline DBP $m m ~ H g$ & $78(70-86)$ & $77(70-85)$ & $80(69-86)$ & 0.92 \\
\hline $\mathrm{PP} m \mathrm{mmg}$ & $74(63-87)$ & $73(62-84)$ & $76(69-90)$ & 0.12 \\
\hline \multicolumn{5}{|l|}{ Qualitative parameters ** } \\
\hline Gender (women) & $46(57.5)$ & $34(63.0)$ & $12(46.2)$ & 0.15 \\
\hline Duration of dialysis $\geq 3$ years & $37(46.3)$ & $24(44.4)$ & $13(50.0)$ & 0.64 \\
\hline High PP & $19(23.8)$ & $10(18.5)$ & $9(34.6)$ & 0.11 \\
\hline Hypertension & $75(94)$ & $62(93)$ & $13(100)$ & 0.31 \\
\hline Antihypertensive medications & $63(79)$ & $5 I(76)$ & $12(92)$ & 0.19 \\
\hline Absence of obesity & $61(76.3)$ & $38(70.4)$ & $23(88.5)$ & 0.07 \\
\hline Morbid obesity & $4(5)$ & $4(7)$ & $0(0)$ & 0.15 \\
\hline Dual factor: & $17(2 \mid .3)$ & $8(14.8)$ & $9(34.6)$ & 0.04 \\
\hline \multicolumn{5}{|l|}{ High PP - nonobese } \\
\hline Pre-existing CV events & $30(37.5)$ & $17(3 \mid .5)$ & $13(50.0)$ & 0.1 \\
\hline Incident CV events & $13(18.3)$ & - & $13(50.0)$ & - \\
\hline Deaths & $23(28.8)$ & - & $23(88.5)$ & - \\
\hline
\end{tabular}

Notes: Data are expressed as: *median (IQR), ${ }^{* *}$ number (\%). High PP $\geq 75$ th percentile of the overall PP values for each gender. Morbid obesity: BMI $\geq 40$ mm $\mathrm{Hg}$. Hypertension: $\mathrm{SBP} \geq 140$ or a $\mathrm{DBP} \geq 90 \mathrm{mmHg}$ or history of hypertension and current use of antihypertensive medication.

Abbreviations: BMI, body mass index; SBP, systolic blood pressure; DBP, diastolic blood pressure; PP, pulse pressure; CV events, cardiovascular events. 
Nonsignificant trends of high frequencies of $\mathrm{PP} \geq 75$ th percentile and BMI $<30 \mathrm{~kg} / \mathrm{m}^{2}$ were found in group 2 compared to group 1 . Frequency of dual variable $\mathrm{PP} \geq 75$ th percentile - BMI $<30 \mathrm{~kg} / \mathrm{m}^{2}$ was higher in group 2 (34.6\%) than in group $1(14.8 \%) ; P=0.04$. Percentages of subjects with pre-existing $\mathrm{CV}$ events and percentages of those using antihypertensive drug therapies were not different between groups.

\section{Univariate Cox analysis}

Unadjusted hazard ratios (HR) of CV events (fatal and nonfatal coronary events and stroke) are presented in Table 2. Pre-existing CV complications were not significantly associated with the risk of events. The risk of $\mathrm{CV}$ events was increased by 2.9-3.5 times with the presence of male gender, high PP, or dual variable wide PP - BMI $<30 \mathrm{~kg} / \mathrm{m}^{2}$. Unadjusted HRs of total mortality were significant for wide $\mathrm{PP}$ and the dual variable. For the dual variable, the $\mathrm{HR}$ of $\mathrm{CV}$ events was $3.5(1.2-10.5) ; P=0.02$ and that of total mortality was $2.9(1.2-6.7) ; P=0.01$. In both cases, the dual variable was the most significant predictor of events.

\section{Multivariate Cox analysis}

In multivariate proportional hazard regression, all models were adjusted for age, gender, duration of dialysis, pre-existing $\mathrm{CV}$ complications and use of antihypertensive medications. Hazard ratios of incident $\mathrm{CV}$ events were not significant for $\mathrm{PP} \geq 75$ th percentile (model 1 ), $\mathrm{BMI}<30 \mathrm{~kg} / \mathrm{m}^{2}$ (model 2 ), $\mathrm{PP} \geq 75$ th percentile and $\mathrm{BMI}<30 \mathrm{~kg} / \mathrm{m}^{2}$ jointly entered in the model (model 3 ) but nearly significant for the dual variable; 2.7 (0.8-8.3); $P=0.09$ (model 4). The hazard ratio of total mortality was significant only for the dual variable wide PP - BMI $<30 \mathrm{~kg} / \mathrm{m}^{2}: 2.4(1.1-5.9) ; P=0.04$.

\section{Discussion}

In this three-year follow-up study on Caribbean T2D subjects undergoing hemodialysis, we found that combination of a wide pulse pressure and body mass index less than $30 \mathrm{~kg} / \mathrm{m}^{2}$ was an independent predictor of total mortality. The results also showed that this dual factor had a higher predictive value for occurrence of death than both variables separately considered. Our findings highlight those of previous studies which reported the reverse epidemiology for obesity in subjects on MHD (Kalantar-Zadeh et al 2005; Kalantar-Zadeh 2006). Contrary to most of previous studies of patients on MHD considering diabetes status as a covariate or a parameter of adjustment, our work was conducted in a diabetic population. Therefore our results showing nearly significant hazard ratios for PP in predicting cardiovascular events or death highlight the need of additional studies on this topic in T2D subjects.

In a large sample of subjects free of overt cardiovascular disease from First National Health and Nutrition Examination Survey (NHANES I), PP increased with increasing of BMI (Domanski et al 2001). This positive correlation was not found in our T2D subjects on MHD. It is not surprising since an "obesity paradox" has been reported in patients with end stage renal disease. In fact, lower BMI or serum albumin was identified as independent predictor of wide PP in diabetics and nondiabetics on MHD (Kalantar-Zadeh et al 2003).

It is suggested that patients in MHD with normal or high normal body weights are faced to malnutrition and inflammation (Qureshi et al 2002; Liu et al 2004) with the latter particularly related to infection (Bellomo et al 2003) In a study evaluating the nutritional status in $128 \mathrm{MHD}$ patients by subjective nutritional assessment, anthropometric parameters,

Table 2 Unadjusted hazard ratios for the occurrence of cardiovascular events and deaths in type 2 Diabetic subjects on maintenance hemodialysis $(\mathrm{N}=80)$, Guadeloupe, 2003-2006

\begin{tabular}{|c|c|c|c|c|c|c|c|}
\hline & \multirow[t]{2}{*}{$\mathbf{N}$} & \multicolumn{3}{|c|}{ Cardiovascular events } & \multicolumn{3}{|c|}{ Death } \\
\hline & & HR & $(95 \% \mathrm{Cl})$ & $P$ & HR & $(95 \% \mathrm{Cl})$ & $P$ \\
\hline Gender (men) & 34 & 3.2 & $(0.9-10.4)$ & 0.05 & 1.5 & $(0.7-3.4)$ & 0.33 \\
\hline Age (/I0 years) & - & 0.9 & $(0.6-1.6)$ & 0.90 & 1.3 & $(0.8-1.9)$ & 0.30 \\
\hline Pre-existing $\mathrm{CV}$ events & 30 & 2.2 & $(0.7-6.6)$ & 0.15 & 2.0 & $(0.9-4.6)$ & 0.09 \\
\hline HD duration $\geq 3$ years & 37 & 1.3 & $(0.5-4.0)$ & 0.60 & 1.1 & $(0.5-2.4)$ & 0.90 \\
\hline Use of antihypertensive medications & 63 & 3.5 & $(0.5-26.8)$ & 0.22 & 1.3 & $(0.5-3.8)$ & 0.63 \\
\hline $\mathrm{BMI}<30 \mathrm{mmHg}$ & 61 & 3.9 & $(0.5-30.6)$ & 0.15 & 3.6 & $(0.8-15.3)$ & 0.08 \\
\hline$P P \geq 75$ th & 19 & 2.9 & $(0.9-8.7)$ & 0.05 & 2.4 & $(I .1-5.5)$ & 0.04 \\
\hline $\mathrm{PP} \geq 75$ th $-\mathrm{BMI}<30$ & 17 & 3.5 & $(1.2-10.5)$ & 0.02 & 2.9 & $(1.2-6.7)$ & 0.01 \\
\hline
\end{tabular}

Abbreviations: $\mathrm{HR}$, hazard ratio; $\mathrm{Cl}$, confidence interval; $\mathrm{HD}$, hemodialysis; $\mathrm{BMI}$, body mass index (cutoff: $30 \mathrm{Kg} / \mathrm{m}^{2}$ ); PP, pulse pressure (cutoff: 75 th percentile by gender). 
Table 3 Adjusted hazard ratios for the occurrence of cardiovascular events and death in type 2 Diabetic subjects on chronic maintenance hemodialysis ( $\mathrm{N}=80$ ), Guadeloupe 2003-2006

\begin{tabular}{|c|c|c|c|c|c|c|c|}
\hline & \multirow[t]{2}{*}{$\mathbf{N}$} & \multicolumn{3}{|c|}{ Cardiovascular events } & \multicolumn{3}{|c|}{ Death } \\
\hline & & $\overline{H R}$ & $(95 \% \mathrm{Cl})$ & $P$ & $\overline{H R}$ & $(95 \% \mathrm{Cl})$ & $P$ \\
\hline \multicolumn{8}{|l|}{ Model I } \\
\hline for $P P \geq 75$ th & 19 & 2.3 & $(0.7-7.4)$ & 0.15 & 2.0 & $(0.8-4.9)$ & 0.13 \\
\hline \multicolumn{8}{|l|}{ Model 2} \\
\hline for $\mathrm{BMI}<30$ & 61 & 1.7 & $(0.2-16.2)$ & 0.63 & 3.0 & $(0.7-14.0)$ & 0.16 \\
\hline \multicolumn{8}{|l|}{ Model 3} \\
\hline for $P P \geq 75$ th & 19 & 2.3 & $(0.7-7.2)$ & 0.16 & 1.8 & $(0.8-4.5)$ & 0.16 \\
\hline for $\mathrm{BMI}<30$ & $6 I$ & 1.6 & $(0.2-15.3)$ & 0.65 & 2.8 & $(0.6-13.1)$ & 0.18 \\
\hline \multicolumn{8}{|l|}{ Model 4} \\
\hline for dual $P P \geq 75$ th - BMI $<30$ & 17 & 2.7 & $(0.8-8.3)$ & 0.09 & 2.4 & $(I . I-5.9)$ & 0.04 \\
\hline
\end{tabular}

Notes: All the models were adjusted for age, gender, time on dialysis, pre-existing cardiovascular events, use of antihypertensive medications. Model I: adjusted HR for $\mathrm{PP} \geq 75$ th percentile (according to gender). Model 2: adjusted HR for $\mathrm{BMI}<30 \mathrm{Kg} / \mathrm{m}^{2}$. Model 3: adjusted HR for PP $\geq 75$ th percentile and BMI $<30 \mathrm{Kg} / \mathrm{m}^{2}$. jointly entered in the model. Model 4: adjusted HR for dual variable $\mathrm{PP} \geq 75 \mathrm{th}-\mathrm{BMI}<30 \mathrm{Kg} / \mathrm{m}^{2}$.

Abbreviations: $\mathrm{HR}$, hazard ratio; $\mathrm{Cl}$, confidence interval; $\mathrm{BMI}$, body mass index (cutoff: $30 \mathrm{Kg} / \mathrm{m}^{2}$ ); PP, pulse pressure (cutoff: 75th percentile by gender).

and several markers of inflammation, the authors concluded that inflammation malnutrition and cardiovascular disease factors appeared interrelated, each additionally contributing to the high mortality in these patients (Qureshi et al 2002).

Pulse pressure was recognized as a crucial risk factor in $\mathrm{CV}$ events and mortality in the general population (Benetos et al 1997; Glynn et al 2000) and was demonstrated to increase cardiovascular risk in diabetic and MHD patients (Aoun et al 2001). In MHD patients, an elevation of systolic blood pressure is generally observed while diastolic BP decrease (Saint-Remy 2005) resulting in a high PP. But, in a study on 1243 MHD patients in Japan, PP was found as a significant predictor for total mortality only in nondiabetic patients (Tozawa al 2002). This blood pressure component exhibited, in our T2D subjects, nearly significant hazard ratio for total mortality and appeared as a significant prognosis factor of deaths when it was combined with normal or high normal BMI in these subjects.

In a cross-sectional analysis, performed on the same Caribbean T2D sample on MHD (Foucan et al 2005), we reported that of the four BP components (SBP, DBP, mean arterial pressure, and PP), only SBP and PP discriminated patients with significant CV history. In this previous study, our results also pointed out a stronger association of preexisting CV complications with PP than with SBP.

The present study has some limitations including its very small sample size for a MHD population and the possibility of misclassifications related to silent myocardial infarction occurring frequently in T2D subjects. A survivor bias may be associated with the fact that this sample was constituted of chronically treated population and was not a cohort of new subjects undergoing HD.
But the strength of our study lies in its longitudinal design on about $85 \%$ of the T2D on MHD from all centers in the island avoiding the bias with study populations selected in single centers. So, we are allowed to take into account, in future guidelines, the results of our report for the management of T2D subjects undergoing hemodialysis.

Elevated PP combined with absence of obesity indicates high risk of death in T2D patients on MHD. Drugs therapies as angiotensin-converting enzyme inhibitors which reduce overall mortality (Prisant 2003) and calcium channel blockers may reduce aortic pulse wave velocity and pulse pressure (Safar et al 1997, 2004; Sharma et al 2007). While it is allowed that some antihypertensive therapy may contribute to decrease arterial stiffness and then PP, the management of BMI is still a matter for debate (Kalantar-Zadeh 2007). In fact, it is difficult to recommend weight gaining or obesity to improve survival on dialysis patients.

We conclude that, in clinical practice, this dual factor may help to identify patients at increase risk of death. We think that, in T2D subjects on MHD, a specific management should be proposed in nonobese subjects with wide PP in order to decrease or prevent the incidence of fatal and nonfatal events.

\section{Disclosure}

This research was supported by the Programme Hospitalier pour la Recherche Clinique (PHRC).

\section{References}

Aoun S, Blacher J, Safar ME, et al. 2001. Diabetes mellitus and renal failure: effects on large artery stiffness. J Hum Hypertens, 15:693-700.

Bellomo G, Lippi G, Saronio P, et al. 2003. Inflammation, infection and cardiovascular events in chronic hemodialysis patients: a prospective study. J Nephrol, 16:245-51. 
Benetos A, Safar M, Rudnichi A, et al. 1997. Pulse pressure: a predictor of long-term cardiovascular mortality in a French male population. Hypertension, 30:1410-5.

Charra B. 2007. [Does hypertension impact on hemodialysis patients mortality?] Nephrol Ther, 3(Suppl 3):S162-9.

Chobanian AV, Bakris GL, Black HR, et al. 2003. Seventh report of the Joint National Committee on Prevention, Detection, Evaluation, and Treatment of High Blood Pressure. Hypertension, 42:1206-52.

Domanski M, Norman J, Wolz M, et al. 2001. Cardiovascular risk assessment using pulse pressure in the first national health and nutrition examination survey (NHANES I). Hypertension, 38:793-7.

Foucan L, Deloumeaux J, Hue K, et al. 2005. High pulse pressure associated with cardiovascular events in patients with type 2 diabetes undergoing hemodialysis. Am J Hypertens, 18:1457-62.

Foucan L, Merault H, Deloumeaux J, et al. 2000. [Survival analysis of diabetic patients on dialysis in Guadeloupe.] Diabetes Metab, 26:307-13.

Glynn RJ, Chae CU, Guralnik JM, et al. 2000. Pulse pressure and mortalty in older people. Arch Intern Med, 160:2765-72.

Kaisar M, Isbel N, Johnson DW. 2007. Cardiovascular disease in patients with chronic kidney disease. A clinical review. Minerva Urol Nefrol, 59:281-97.

Kalantar-Zadeh K, Block G, Humphreys MH, et al. 2003. Reverse epidemiology of cardiovascular risk factors in maintenance dialysis patients. Kidney Int, 63:793-808.

Kalantar-Zadeh K, Kopple JD, Kilpatrick RD, et al. 2005. Association of morbid obesity and weight change over time with cardiovascular survival in hemodialysis population. Am J Kidney Dis, 46:489-500.

Kalantar-Zadeh K, Kopple JD. 2006. Obesity paradox in patients on maintenance dialysis. Contrib Nephrol, 151:57-69.

Kalantar-Zadeh K. 2007. What is so bad about reverse epidemiology anyway? Semin Dial, 20:593-601.

Kopple JD. 2005. The phenomenon of altered risk factor patterns or reverse epidemiology in persons with advanced chronic kidney failure. Am J Clin Nutr, 81:1257-66.
Liu Y, Coresh J, Eustace JA, et al. 2004. Association between cholesterol level and mortality in dialysis patients: role of inflammation and malnutrition. JAMA, 291:451-9.

Nawrot TS, Staessen JA, Thijs L, et al. 2004. Should pulse pressure become part of the Framingham risk score? J Hum Hypertens, 18:279-86.

Nurmohamed SA, Nube MJ. 2005. Reverse epidemiology: paradoxical observations in haemodialysis patients. Neth J Med, 63:376-81.

Prisant LM. 2003. Diabetes mellitus and hypertension: a mandate for intense treatment according to new guidelines. Am J Ther, 10:363-9.

Qureshi AR, Alvestrand A, Divino-Filho JC, et al. 2002. Inflammation, malnutrition, and cardiac disease as predictors of mortality in hemodialysis patients. J Am Soc Nephrol, 13(Suppl 1):S28-36.

Safar ME, Vaisse B, Blacher J, et al. 2004. Pulse pressure monitoring of open antihypertensive therapy. Am J Hypertens, 17:1088-94.

Safar ME, van Bortel LM, Struijker-Boudier HA. 1997. Resistance and conduit arteries following converting enzyme inhibition in hypertension. J Vasc Res, 34:67-81.

Saint-Remy A, Krzesinski JM. 2005. Optimal blood pressure level and best measurement procedure in hemodialysis patients. Vasc Health Risk Manag, 1:235-44.

Sharma SK, Ruggenenti P, Remuzzi G. 2007. Managing hypertension in diabetic patients-focus on trandolapril/verapamil combination. Vasc Health Risk Manag, 3:453-65.

Tozawa M, Iseki K, Iseki C, et al. 2002. Pulse pressure and risk of total mortality and cardiovascular events in patients on chronic hemodialysis. Kidney Int, 61:717-26.

Zager PG, Nikolic J, Brown RH, et al. 1998. “U” curve association of blood pressure and mortality in hemodialysis patients. Medical Directors of Dialysis Clinic, Inc. Kidney Int, 54:561-9. 